\title{
Blockchain-based sharing services: What blockchain technology can contribute to smart cities
}

\author{
Jianjun Sun ${ }^{1}$, Jiaqi Yan ${ }^{1 *}$ (D) and Kem Z. K. Zhang ${ }^{2}$
}

\author{
* Correspondence: \\ jiaqiyan@nju.edu.cn \\ ${ }^{1}$ School of Information \\ Management, Nanjing University, \\ Nanjing, China \\ Full list of author information is \\ available at the end of the article
}

\begin{abstract}
Background: The notion of smart city has grown popular over the past few years. It embraces several dimensions depending on the meaning of the word "smart" and benefits from innovative applications of new kinds of information and communications technology to support communal sharing.

Methods: By relying on prior literature, this paper proposes a conceptual framework with three dimensions: (1) human, (2) technology, and (3) organization, and explores a set of fundamental factors that make a city smart from a sharing economy perspective.

Results: Using this triangle framework, we discuss what emerging blockchain technology may contribute to these factors and how its elements can help smart cities develop sharing services.

Conclusions: This study discusses how blockchain-based sharing services can contribute to smart cities based on a conceptual framework. We hope it can stimulate interest in theory and practice to foster discussions in this area.
\end{abstract}

Keywords: Smart city, Blockchain, Sharing economy, Internet of Things (IoT), Smart contract

\section{Background}

Nowadays, cities face complex challenges to improve their citizens' quality of life. According to the 2014 United Nations (UN) World Urbanization Prospects report (UnitedNations 2014), more than half of the global population now lives in urban areas, and an additional 2.5 billion people are predicted to move to cities by 2050 . Due to urban concentration, people's living conditions have been impacted by increased traffic jams, carbon dioxide, greenhouse gas emissions, and waste disposal.

The notion of "smart city" is a response to these problems; it has gained popularity over the past few years. Many cities define themselves as "smart" when they identify some of their own characteristics as being so (such as broadband connectivity, digital inclusion, and knowledge workforce). A common underlying fact is that these smart cities benefit from innovative applications of new kinds of information and communications technology (ICT) to support communal sharing (Agyeman and McLaren 2014).

In the literature, smart city is a broad idea that includes many aspects of urban life (Chourabi et al. 2012) and is also a fuzzy concept that has been used in ways that are 
not always in accordance with each other (Cocchia 2014). The notion embraces several different dimensions depending on the meaning attributed to the word "smart" and the label "smart city." Some examples include digital city (Couclelis 2004), intelligent city (Komninos 2006), knowledge city (Ergazakis et al. 2004), and ubiquitous city (Anthopoulos and Fitsilis 2010). The ambiguity of the concept causes difficulty in understanding how information technology (IT) adoption impacts smart cities' development (Komninos et al. 2013).

As such, to grasp the effects of emerging blockchain technology on the growth of smart cities, it calls forth the use of an observation perspective to identify their essential elements. To address this problem, we propose a triangle framework of human, technology, and organization to identify the features of smart cities from the angle of the sharing economy. We apply this framework to analyze the influence of blockchains on building smart cities. The rest of the paper is arranged as follows. In Section Smart cities and the sharing economy, we explore the relationship between the sharing economy and smart cities. We propose the aforementioned triangle framework in Section A conceptual framework of smart cities from a sharing economy perspective. In Section Blockchain-based sharing services: Toward smart cities, we analyze the features of the management and computing of blockchain-based sharing services within the framework and consider what blockchains may contribute to smart city development. In Section Conclusions, we draw our conclusions.

\section{Smart cities and the sharing economy}

A city cannot adequately be called "smart" using specific or limited sectoral improvements. A "smart" city involves horizontally cumulative elements such as smart governance, smart mobility, smart living, the smart use of natural resources, smart citizens, and smart economy, all taken together (Gori et al. 2015). Nevertheless, because of space constraints and the population density of urban living, cities are naturally designed to be sharing economies with consumption involving access to shared resources over asset ownership (Sundararajan 2014). There are various ways of using modern technologies to create efficient economies and societies, yet sharing is one of the most important characteristics of smart cities (Agyeman and McLaren 2014).

Figure 1 shows an illustration of the link between the sharing economy and smart cities. In the core, smart city is propelled by societal drivers, economic drivers, and technology enablers. In the figure's outer ring, the ultimate goal of smart city is to achieve

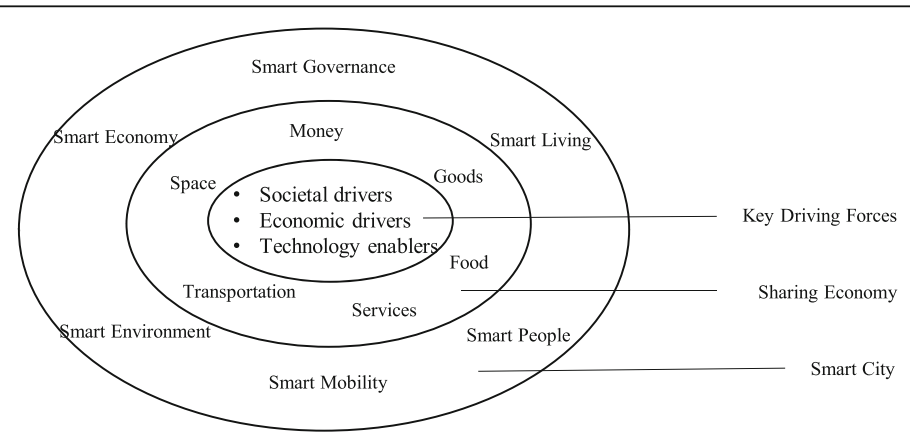

Fig. 1 Smart cities and the sharing economy 
smart governance, living, people, mobility, environment, and economy (Caragliu et al. 2011). In the middle ring, smart city's growth benefits from improving the use of urban resources such as space, transportation, services, food, goods, and money. Since the sharing economy concerns how to share urban resources, studying smart city through the lens of the sharing economy can help us better understand how it expands from the angle of resource allocation.

The sharing economy can be defined as an economic/social model that broad sectors of the population can employ to collaboratively make use of under-utilized assets, in which supply and demand are interacting for the supply side to directly provide products/services. The overall aim of a sharing business, which can be both profit-oriented and non-profit oriented, is to improve the use of under-utilized assets and reduce transaction costs (Gori et al. 2015). On the supply side, individuals can offer things such as short-term rentals of their idle vehicles, or spare rooms in their apartments or houses. On the demand side, consumers can benefit from renting goods at lower cost or with lower transactional overhead than buying or renting through a traditional provider (Economist 2013).

The sharing economy has created a number of opportunities for smart cities in terms of improving asset utilization and effectively reducing transaction costs and waste (Tedjasaputra and Sari 2016). Improving the use of assets implies numerous positive consequences, for instance, energy saving and congestion decreasing. While sharing goods and services in marketplaces has a long history, and old-fashioned face-to-face sharing still happens in communities everywhere, Internet intermediaries can now support these transactions and match supply and demand in real time on a large scale. On websites, people can find rooms to stay in (Airbnb, Roomorama), as well as for using tools (SnapGoods), cars, bikes (RelayRides, Wheelz), and ad hoc taxi services (Uber, Lyft). These websites unlock the value inherent in sharing spare resources as two-sided platforms, and offer many advantages to attract the two groups via network effects (Eisenmann et al. 2006).

The sharing economy is driven by enabling technologies of digital connectivity, which provide the foundation of these innovations in the sense that it allows immediacy (Gori et al. 2015). Real-time information and knowledge gathered by individuals are key to tackling the inefficient use of under-utilized assets and making a city "smart." Citizens, objects, and utilities in smart cities can link up seamlessly by using ubiquitous technologies to significantly improve information sharing regarding the status and exchange of idle assets. With digital connectivity, people can rent out spare bedrooms and basements, keep parking spaces full, ride an idle bicycle in the street, and take a shared cab with a stranger heading in the same direction.

\section{Methods}

\section{A conceptual framework of smart cities from a sharing economy perspective}

To understand the development of smart cities from the angle of a sharing service, we propose a conceptual framework of smart cities based on the literature. According to the conceptual classification of smart cities in previous studies (Cocchia 2014; Nam and Pardo 2011), technology, human, and organization represent the terms most frequently used to describe smart cities. 


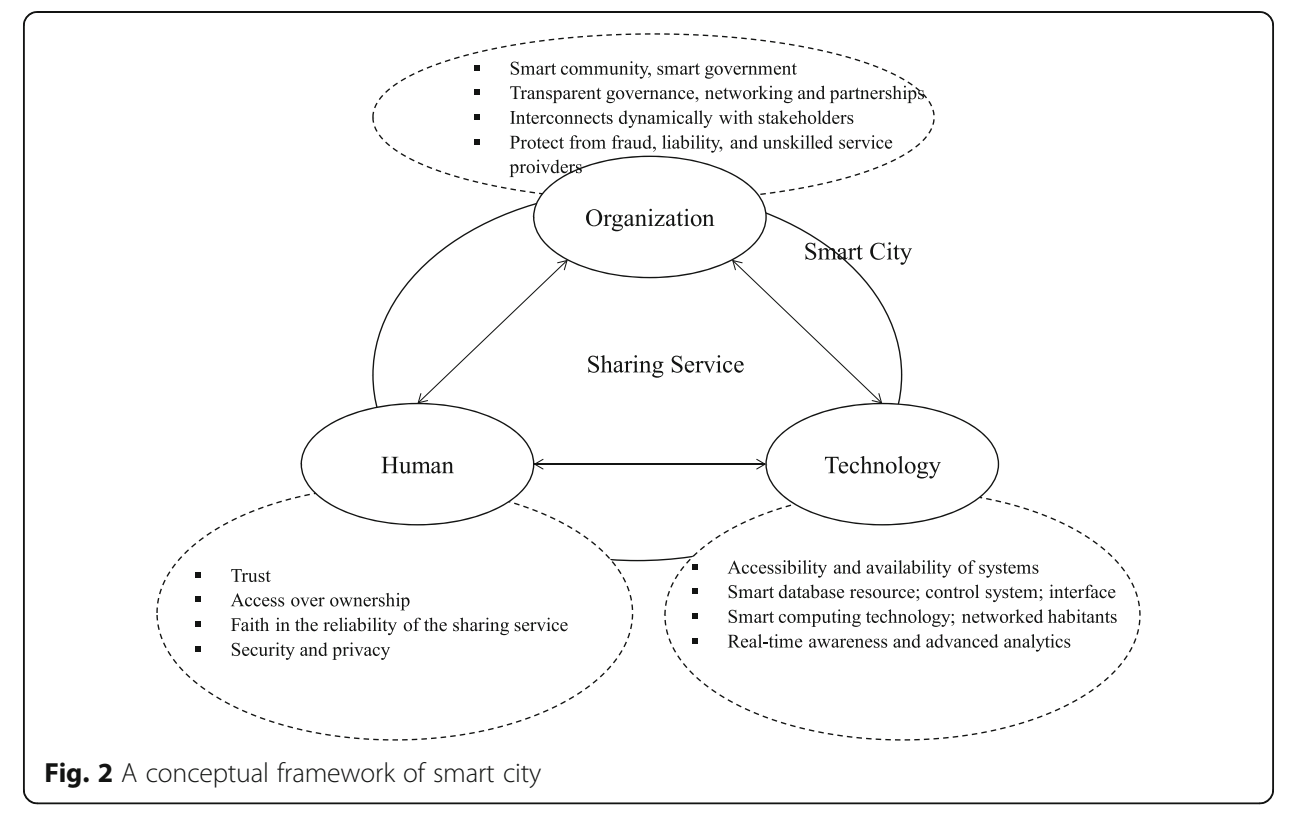

As shown in Fig. 2, smart city is based on human, technology, and organization, and there can be service relationships among them. Technology is based on using ICT to transform life and work within a city in relevant ways. Notions related to this aspect include digital city (Aurigi 2005; Ishida and Isbister 2000), virtual city (Schuler 2001), information city (Anthopoulos and Fitsilis 2010), wired city (Hollands 2008), ubiquitous city (Anthopoulos and Fitsilis 2010), and intelligent city (Komninos 2006). The human dimension is based on people, education, learning, and knowledge; concepts related to it include learning city (Larsen 1999; McFarlane 2011) and knowledge city (Ergazakis et al. 2004). The element of organization is based on governance and policy because cooperation between stakeholders and institutional governments is very important to design and implement smart city initiatives; this component includes ideas such as smart community, sustainable city (Bătăgan 2011), and green city (Kahn and Mills 2006).

From the viewpoint of a sharing service, technology is critical for a city to become smart since technology infrastructure significantly and fundamentally changes how resources are shared within it. A sharing service with a technology dimension stresses the accessibility and availability of systems (Giffinger and Gudrun 2010; Giffinger and Pichler-Milanović 2007). Al-Hader et al. (2009) specified technological components within a pyramid that represents a smart city's development; the pyramid is composed of smart database resources, smart control systems, and smart interfaces. Smart database resources collect information about a smart city's resources. Smart control systems organize and schedule resources in a smart way, while people access and share resources via smart interfaces. In terms of technology, a smart city is also regarded as a collection of smart computing technologies applied to critical infrastructure elements and services (Washburn et al. 2009). As portrayed by Forest et al. (2009) in the roadmap, the process of making cities evolves from smart places to networked inhabitants. From the standpoint of a sharing service, smart cities provide IT systems with real-time awareness of urban resources, while advanced analytics help people make more intelligent choices about alternatives and take actions that optimize the use of under-utilized assets. 
Other issues related to technology infrastructure include technoware (Malek 2009), and how technology and the physical environment are arranged (Boulton et al. 2011).

The category of human factors from the angle of a sharing service highlights the role of human infrastructure, human capital, and education in urban development (Boulton et al. 2011). A smart city is a humane one that offers multiple opportunities to exploit its human potential and help people lead creative lives. As a dark side of the sharing economy (Malhotra and Alstyne 2014), trust, among all other human factors, is the most important one challenging the sharing economy in smart cities. Sharing involves dividing something among relative strangers; thus, trust plays an important role in supporting both people and services to overcome perceptions of uncertainty and risk when making a decision (Belk 2014). The general aim of trust is to obtain a good feeling, ensuring users' faith in the reliability of sharing service providers and other asset users, and establishing an impression of security during use or transactions (Bhattacherjee 2002; Wirtz and Lwin 2009). In addition to security, privacy is another facet of trust in the sharing economy (Dillahunt and Malone 2015).

The organization of smart cities focuses on the support of government and policies for governance, and comprises various elements such as smart community, smart government, integrated and transparent governance, networking and partnerships (Nam and Pardo 2011). Considering stakeholders for governance is fundamental to a smart city's architecture (Nam and Pardo 2011). A smarter government does more than simply regulate the outputs of economic and social systems; it also interconnects dynamically with stakeholders such as citizens, communities, and businesses (Palmisano 2008). From the angle of a sharing service, there is a need for governance to protect users of sharing services from fraud, liability, and unskilled service providers (Ranchordás 2015).

\section{Results}

\section{Blockchain-based sharing services: Toward smart cities}

To understand the blockchain solution, we summarize the features of the management and computing of blockchain-based sharing services via the triangle framework of service orientation (Zhao et al. 2008). Altogether, there are six types of service relationships

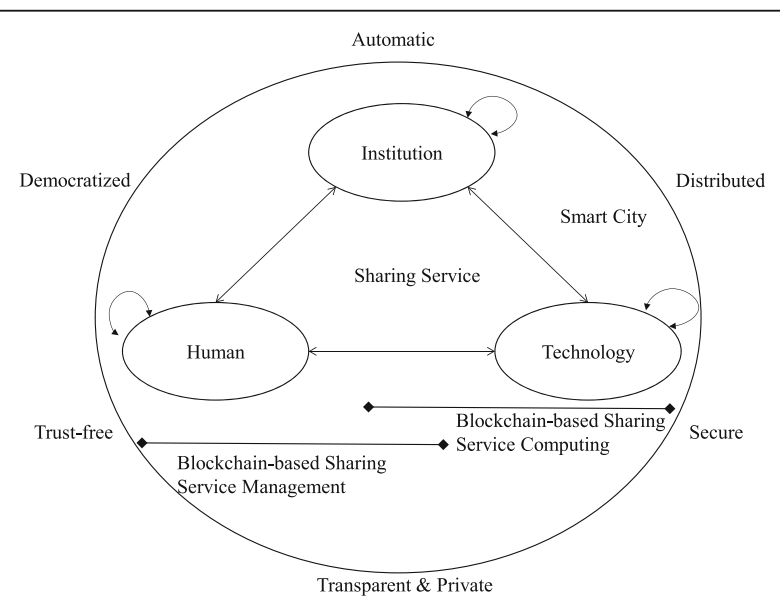

Fig. 3 Features of the management and computing of blockchain-based sharing services 
among human, technology, and organization. As shown in Fig. 3, where each arrow indicates a type of service relationship, the management of blockchain-based sharing services mainly deals with relationships involving people, while the computing of blockchainbased sharing services mostly relates to relationships involving technology.

In the blockchain-based approach, being trust-free is a central feature of people's relationships. The Economist describes blockchain as "the trust machine," indicating that it takes care of trust issues between individuals (Economist 2015). In other words, the economic system, which is built on blockchain technology, runs without people, thus making a transaction "trust-free." Historically, trust has underpinned business, often involving a reliable third party, which is expensive. Blockchain technology provides a viable alternative to eliminate intermediaries, thereby lowering operational costs and increasing the efficiency of a sharing service. With blockchain technology, the world's most fundamental commercial interactions can be re-imagined; the door to invent new styles of digital interactions in trust-free sharing services has been opened.

The dynamic of people being trust-free in blockchain business services is based on transparency and privacy in the service relationship between human and technology. Blockchain technology enables people to access the records of every transaction they make, as it permanently records transaction history at every node of the blockchain (SpendMatters 2015). Furthermore, blockchain transactions are recorded using public and private keys (i.e., long strings of characters that people cannot read); thus, people can choose to remain anonymous to protect their privacy while enabling third parties to verify their identity (Economist 2016). Enigma (enigma.media.mit.edu), a cloud platform created by the Massachusetts Institute of Technology (MIT), is an example of blockchain technology; it allows different parties to jointly store and run computations on data while keeping the data itself completely private.

Due to the change in the trust model of blockchain-based system, the service relationship between the elements of human and organization in blockchain-based sharing services has become democratized. In blockchain-based sharing services, trust is not placed in an individual, but rather distributed across the entire population. The use of central authorities is replaced by a community of peers in the form of a peer-to-peer network; no one can unilaterally take actions on behalf of the community. In such a democratized context, governments cannot manipulate an election by coercing individuals, and corporations cannot unilaterally break the rules of the system.

Automation in blockchain-based sharing services is the most salient feature of service relationships between organizations. Based on the features of being trust-free and democratized, blockchain technology has enabled business transactions with strangers without the need for a trusted intermediary; meanwhile, software can automate much of the transaction process, allowing contractual promises to be enforced without human involvement. The automation of doing business in blockchain-based business services has attracted significant interest in various industries. A German startup that specializes in blockchain applications called Slock.it (www.slock.it) offers smart locks called "Slocks" controlled by Ethereum, a public platform founded on blockchain-based distributed computing. The owner of a Slock can set a deposit amount and a price for renting his property, and a customer can pay the deposit through a transaction to the Ethereum blockchain to get permission to open and close the Slock. With Slock.it, 
locks are controlled by automatically executing business contracts in the blockchain, and businesses such as renting Airbnb apartments can become fully automated.

Elements such as being smart, distributed, secure, shared, and encrypted in the computing of blockchain-based sharing services provide the foundation for being trust-free, democratized, automatic, transparent, and private. The computing of blockchain-based sharing services supports the automation of business transactions and services. Enabled by blockchain technology, Internet of Things (IoT) devices can participate in trust-free transactions, and contracts can be captured in computing codes to automatically perform the obligations that parties have committed to in an agreement. The concept of "smart contract", proposed by Nick Szabo in 1993, has now been implemented in the Ethereum blockchain; a smart contract contains code functions and can interact with other contracts, make decisions, store data, and send ether to others. Watson IoT, a cognitive system developed by International Business Machines (IBM), involves a blockchain that enables information from devices - such as locations based on radiofrequency identification (RFID), barcode scanned events, or device-reported data - to be conveyed to blockchain-based ledgers to update or validate smart contracts (O'Connor 2016). Within a web of contextualized smart contracts, software agents could be set up to dynamically manage each distributed autonomous organization, connecting physical nodes in a network (such as computers, smartphones, and sensors) to devices (such as smart TVs, fridges, and cars). In the long term, the computing of blockchain-based sharing services - along with the highly efficient IoT powered by the Internet and a web of agents, smart transactions, and contracts - will automate sharing business (Morrison 2016).

The distributed nature in a service relationship between technology and organization is an important aspect of the computing of blockchain-based sharing services. Distributed computing and distributed algorithms allow democratized nodes in a blockchain to reach a consensus. In a distributed system, different nodes need to prove that they are working toward the same goal and ensure consistency. Bitcoin creator Satoshi Nakamoto proposed the proof of work (POW) mechanism to create distributed consensus in a process of repeatedly running hashing algorithms to validate electronic transactions, or so-called bitcoin mining (Nakamoto 2008). According to IBM (IBM 2015), adopting distributed computing to process hundreds of billions of IoT transactions that occur daily can significantly reduce costs associated with installing and maintaining large amounts of centralized data; thus, blockchain technology has democratized devices in terms of distributed computing, which will ensure the future of the IoT.

Security in blockchain-based service computing is a significant backbone of trustfree sharing services. Security is comprised of confidentiality, integrity, and availability; it requires the concurrent existence of: (1) the availability for authorized actions only; (2) confidentiality; and (3) integrity where "improper" means "unauthorized" (Avizienis et al. 2004). As the blockchain is decentralized, the availability of blockchain data does not rely on any third parties. With private and public key cryptography, part of a blockchain's underlying protocol, confidentiality becomes virtually indisputable. Integrity is ensured since the blockchain can be regarded as a distributed file system where participants keep copies of files and agree on changes by consensus. The history of blockchain-based applications such 
as Bitcoin and Ethereum has proven the sustainability and continuous improvement of security in blockchain-based service computing.

\section{Conclusions}

Tracing the meaning of the word "smart" in the label "smart city" from the sharing economy viewpoint can help us understand the requirements of smart cities, and how adopting new technology can help to build them. In this paper, based on a conceptual framework, we discuss how the features of blockchain technology may contribute to smart city development through sharing services. We hope this paper will be a starting point for more research and discussions on the design and adoption of blockchainbased sharing services for smart cities.

\section{Funding}

This research is supported by the Research Project 12DDB012 from Jiangsu Social Science Research Foundation, and partially supported by grants from National Natural Science Foundation of China (No. 71671174, 71472172) and Fundamental Research Funds for the Central Universities of China (No. WK2040160013).

\section{Authors' contributions}

$J S$ and JY initiated this project and conceptualized the contents of the research. KZKZ has been involved in drafting the manuscript. All authors read and approved the final manuscript.

\section{Competing interests}

The authors declare that they have no competing interests.

\section{Author details}

${ }^{1}$ School of Information Management, Nanjing University, Nanjing, China. ${ }^{2}$ School of Management, University of Science and Technology of China, Hefei, China.

Received: 7 November 2016 Accepted: 24 November 2016

Published online: 13 December 2016

\section{References}

Agyeman J, McLaren D (2014) 'Smart Cities' Should Mean 'Sharing Cities'. In: Times

Al-Hader M, Rodzi A, Sharif AR, Ahmad N (2009) Smart city components architicture, 2009 International Conference on Computational Intelligence, Modelling and Simulation, IEEE., pp 93-97

Anthopoulos L, Fitsilis P (2010) Intelligent Environments (IE), 2010 Sixth International Conference on, IEEE., pp 301-306 Aurigi A (2005) Making the digital city: the early shaping of urban internet space. Ashgate Publishing, Ltd, Hampshire Avizienis A, Laprie JC, Randell B, Landwehr C (2004) Basic concepts and taxonomy of dependable and secure computing. IEEE Trans Dependable Secure Comput 1(1):11-33

Bătăgan L (2011) Smart cities and sustainability models. Inf Econ 15(3):80-87

Belk R (2014) You are what you can access: Sharing and collaborative consumption online. J Bus Res 67(8):1595-1600 Bhattacherjee A (2002) Individual trust in online firms: Scale development and initial test. J Manag Inf Syst 19(1):211-241

Boulton A, Brunn SD, Devriendt L (2011) 18 cyberinfrastructures and 'smart'world cities: physical, human and soft infrastructures. In: International Handbook of Globalization and World Cities., p 198

Caragliu A, Del Bo C, Nijkamp P (2011) Smart cities in Europe. J Urban Technol 18(2):65-82

Chourabi H, Nam T, Walker S, Gil-Garcia JR, Mellouli S, Nahon K, Pardo TA, Scholl HJ (2012) Understanding smart cities: An integrative framework, System Science (HICSS), 2012 45th Hawaii International Conference on, IEEE., pp 2289-2297

Cocchia A (2014) Smart and Digital City: A Systematic Literature Review. Smart City: How to Create Public and Economic Value with High Technology in Urban Space. Dameri RP and Rosenthal-Sabroux C (eds). Springer International Publishing, Cham, p 13-43

Couclelis H (2004) The construction of the digital city. Environ Plann B Plann Des 31(1):5-19

Dillahunt TR, Malone AR (2015) The Promise of the Sharing Economy among Disadvantaged Communities. In: Proceedings of the 33rd Annual ACM Conference on Human Factors in Computing Systems. ACM, Seoul, pp 2285-2294

Economist (2013) The rise of the sharing economy, The Economist

Economist (2015) The promise of the blockchain: The trust machine. In: The Economist., http://www.economist.com/ news/leaders/21677198-technology-behind-bitcoin-could-transform-how-economy-works-trust-machine

Economist (2016) The blockchain in finance: Hype springs eternal. In: The Economist., http://www.economist.com/ news/finance-and-economics/21695068-distributed-ledgers-are-future-their-advent-will-be-slow-hype-springs

Eisenmann T, Parker G, Van Alstyne MW (2006) Strategies for two-sided markets. Harv Bus Rev 84(10):92

Ergazakis K, Metaxiotis K, Psarras J (2004) Towards knowledge cities: conceptual analysis and success stories. J Knowl Manag 8(5):5-15

Forest F, Lavoisy O, Eurich M, Van Gurp J, Wilson D (2009) Roadmap for Real World Internet applications, Towards the Future Internet-A European Research Perspective., pp 325-334

Giffinger R, Gudrun H (2010) Smart cities ranking: an effective instrument for the positioning of the cities? ACE Archit City Environ 4(12):7-26 
Giffinger R, Pichler-Milanović N (2007) Smart cities: Ranking of European medium-sized cities, Centre of Regional Science, Vienna University of Technology

Gori P, Parcu PL, Stasi ML (2015) Smart Cities and Sharing Economy, vol 96, Robert Schuman Centre for Advanced Studies Research Paper No. RSCAS

Hollands RG (2008) Will the real smart city please stand up? Intelligent, progressive or entrepreneurial? City 12(3):303-320

IBM (2015) Device democracy: Saving the future of the Internet of Things., http:/www-935.bm.com/services/us/gbs/ thoughtleadership/internetofthings/

Ishida T, Isbister K (eds) (2000) Digital cities: technologies, experiences, and future perspectives. Springer Science \& Business Media, Berlin

Kahn ME, Mills ES (2006) Green cities: urban growth and the environment. Brookings Institution Press, Washington

Komninos N (2006) The architecture of intelligent clities: Integrating human, collective and artificial intelligence to enhance knowledge and innovation, Intelligent Environments, 2006. IE 06. 2nd IET International Conference on, IET., pp 13-20

Komninos N, Pallot M, Schaffers H (2013) Special Issue on Smart Cities and the Future Internet in Europe. J Knowl Econ 4(2):119-134

Larsen K (1999) Learning cities: the new recipe in regional development, vol 217/218, Organisation for Economic Cooperation and Development. The OECD Observer., p 73

Malek JA (2009) Informative global community development index of informative smart city. Proceedings of the 8th WSEAS International Conference on Education and Educational Technology.

Malhotra A, Alstyne MV (2014) The dark side of the sharing economy \& hellip; and how to lighten it. Commun ACM 57(11):24-27

McFarlane C (2011) Learning the city: knowledge and translocal assemblage. Vol. 101. John Wiley \& Sons, Oxford

Morrison A (2016) Blockchain and smart contract automation: How smart contracts automate digital business., http://www.pwc.com/us/en/technology-forecast/blockchain/digital-business.html

Nakamoto S (2008) Bitcoin: A peer-to-peer electronic cash system

Nam T, Pardo TA (2011) Conceptualizing smart city with dimensions of technology, people, and institutions, Proceedings of the 12th Annual International Digital Government Research Conference: Digital Government Innovation in Challenging Times, ACM., pp 282-291

O'Connor C (2016) What blockchain means for the Internet of Things. In: IBM (ed) Internet of Things Blog., https://www.ibm.com/blogs/internet-of-things/watson-iot-blockchain/

Palmisano SJ (2008) A smarter planet: the next leadership agenda. IBM November (6):1-8

Ranchordás S (2015) Does sharing mean caring: Regulating innovation in the sharing economy. Minn JL Sci Tech 16:413

Schuler D (2001) Digital cities and digital citizens. In Kyoto Workshop on Digital Cities. Springer, Berlin Heidelberg, p $71-85$

SpendMatters (2015) Why Bitcoin's Blockchain Technology Could Revolutionize Supply Chain Transparency. In: Spend Matters., http://spendmatters.com/2015/11/09/why-bitcoins-blockchain-technology-could-revolutionize-supplychain-transparency/

Sundararajan A (2014) Peer-to-peer businesses and the sharing (collaborative) economy: Overview, economic effects and regulatory issues, Written testimony for the hearing titled The Power of Connection: Peer to Peer Businesses, January

Tedjasaputra A, Sari E (2016) Sharing Economy in Smart City Transportation Services. In: Proceedings of the SEACHI 2016 on Smart Cities for Better Living with HCl and UX. ACM, San Jose, pp 32-35

UnitedNations (2014) World Urbanization Prospects, The Population Division of the Department of Economic and Social Affairs of the United Nations

Washburn D, Sindhu U, Balaouras S, Dines R, Hayes N, Nelson L (2009) Helping ClOs understand "smart city" initiatives. Growth 17(2):1-15

Wirtz J, Lwin MO (2009) Regulatory focus theory, trust, and privacy concern. J Serv Res 12(2):190-207

Zhao JL, Hsu C, Jain HK, Spohrer JC, Tanniru M, Wang HJ (2008) ICIS 2007 Panel report: bridging service computing and service management: how MIS contributes to service orientation. Commun Assoc Inf Syst 22(1):22

\section{Submit your manuscript to a SpringerOpen ${ }^{\circ}$ journal and benefit from:}

- Convenient online submission

- Rigorous peer review

- Immediate publication on acceptance

- Open access: articles freely available online

- High visibility within the field

- Retaining the copyright to your article

Submit your next manuscript at $\boldsymbol{\nabla}$ springeropen.com 